\title{
Tıbbi Adaçayı (Salvia officinalis L.)'nda Uçucu Yağ Oranı ve Kompozisyonu Üzerine Ontogenetik Varyabilitenin Etkisi
}

\author{
Nimet Katar ${ }^{1}$ Duran Katar ${ }^{2 *}$ Doğan Aydın ${ }^{1} \quad$ Murat Olgun ${ }^{2}$ \\ ${ }^{1}$ Eskişehir Osmangazi Üniversitesi, Fen Bilimleri Enstitüsü, Eskişehir \\ ${ }^{2}$ Eskişehir Osmangazi Üniversitesi, Ziraat Fakültesi, Tarla Bitkileri Bölümü, Eskişehir
}

Geliş tarihi (Received): 21.01.2018 Kabul tarihi (Accepted): 04.07.2018

\section{Anahtar kelimeler: \\ Salvia officinalis L., uçucu yağ oranı ve komponentleri, ontogenetik varyabilite}

*Sorumlu yazar

durankatar@gmail.com

\begin{abstract}
Özet. Bu araştırma Eskişehir ekolojik koşullarında 2015 yılında yürütülmüştür. Çalışmada bitkiler dört farklı gelişim döneminde (çiçeklenme öncesi, çiçeklenme başlangııı, tam çiçeklenme ve tohum bağlama dönemi) üç tekerrürlü olarak hasat edilmiştir. Örnekler kurutma dolabında $\left(35^{\circ} \mathrm{C}\right)$ kurutulduktan sonra su distilasyonu yöntemiyle uçucu yağ oranları belirlenmiştir. Uçucu yağların bileşenleri ise GS/MS ile tayin edilmiştir. Araştırmanın sonuçlarına göre, uçucu yağ oranı farklı gelişme dönemlerinden istatistiki olarak önemli düzeyde etkilenmiştir. Nitekim drog yaprakta uçucu yağ oranı \%1.0-2.0 arasında değişmiştir. En yüksek uçucu yağ oranı (\%2.0) çiçeklenme öncesi dönemde yapılan hasattan elde edilirken, en düşük uçucu yağ oranı (\%1.0) tam çiçeklenme ve tohum bağlama döneminde yapılan hasattan elde edilmiştir. Diğer taraftan, $\alpha$-thujone ve camphor tüm gelişme dönemlerinde ana bileşen olarak tespit edilmiştir. En yüksek $\alpha$-thujone oranı (\%47.24) tam çiçeklenme döneminde yapılan hasattan elde edilirken, en düşük oran (\%23.09) ise çiçeklenme başlangıcı döneminde yapılan hasattan elde edilmiştir. Bu yüzden, tıbbi adaçayından $\alpha$-thujone oranı düşük ve en yüksek düzeyde uçucu yağ elde etmek için hasadın çiçeklenme başlangıcı döneminde yapılması tavsiye edilmektedir.
\end{abstract}

\section{Effect of Ontogenetic Variability on Essential Oil Content and Its Components in Sage (Salvia officinalis L.)}

\footnotetext{
Keywords:

Salvia officinalis L., essential oil content and components, ontogenetic variability
} 
Katar ve ark., Tıbbi Adaçayı (Salvia officinalis L.)'nda Uçucu Yağ Oranı ve Kompozisyonu Üzerine Ontogenetik Varyabilitenin Etkisi

\section{GiRiş}

Dünyada, çoğunlukla aromatik bitkileri içeren Lamiaceae/Labiatae (Ballıbabagiller) familyası 45 farklı cins ile temsil edilmektedir (Şenkal ve ark., 2012; Yılmaz ve Gokduman 2015). Bu familyanın Salvia cinsine ait, tropik ve subtropik bölgelerinde yayılış gösteren 1000 'e yakın türü bulunmakta ve bu türler Amerika'da, Asya'da, Avrupa'nın ve Kuzey Afrika'nın Akdeniz'i kuşatan sahil bölgelerinde yayılış göstermektedir (Başa et al., 2012; Lakusic et al., 2013; Kilic 2016). Salvia officinalis, ülkemiz florasında doğal olarak bulunmamakla birlikte ekonomik önemi olan ve yetiştiriciliği konusunda çalışmaların yürütülmekte olduğu bir tür olup, son yıllarda kültür koşullarında konvansiyonel ve organik tarım sistemlerinde üretimi giderek artmaktadır. Ayrıca bu tür süs bitkisi olarak da park ve bahçelerde değerlendirilmektedir (Ekren ve ark., 2007; Bayram ve ark., 2010; Özcan ve ark., 2014; Yılmaz ve Gokduman 2015; Kilic 2016).

Adaçayının drog olarak kullanılan kısımları, yaprakları (Folia Salviae), çiçekleri (Flores Salviae) ve yaprak ve çiçeklerinden elde edilen uçucu yağı (Oleum Salviae) olup, en önemli biyoaktif maddesi ise içermiş oldukları uçucu yağdır (Ekren ve ark., 2007; Başa et al al., 2012; Yılmaz ve Gokduman 2015). Bitkinin taze yapraklarında uçucu yağ oranı \% 0.38 dolayında iken, drog yapraklarda bu oran \% 0.50-2.50 arasında değişmektedir (Başa et al., 2012; Yılmaz ve Gokduman 2015). Kodekslerde ise uçucu yağ oranının en az \%1.5 olması istenmektedir (Ekren ve ark., 2007). Tıbbi adaçayı günümüz Avrupa'sında tıbbi kullanımı resmen kabul edilmiş bir bitkidir (Ekren ve ark., 2007). Bitkinin uçucu yağının ana bileşenleri alfa ve beta tujon, 1.8sineol, kafur, borneol ve bornilasetattır. Hatta bazı uçucu yağlarda timol ve karvakrol'un bulunduğu da bildirilmektedir (Ekren ve ark., 2007; Aziz et al., 2013).

Tıbbi ve aromatik bitkilerin uçucu yağ oranı ve bileşenleri çevrenin, genetik faktörlerin ve yetiştiricilik uygulamalarının etkisi altında değişim göstermektedir (Hadiana et al., 2008). Aynı şekilde aromatik bitkilerin uçucu yağ oranı ve bileşimi bitkilerin hasadının yapıldığı gelişim dönemine bağlı olarak da farklılık göstermektedir. Bu durum dikkate alındığında aromatik bitkilerin kültürü yapılırken, en yüksek oranda uçucu yağ ve üretim amacına en uygun olan uçucu yağ kompozisyonuna sahip yağların elde edilmesi için uygun zamanda bitkilerin hasadının yapılması büyük öneme sahiptir. Yapılan çok sayıda araştırma en uygun hasat zamanının üretimde kullanılan bitkinin türüne ve üretimin yapıldığı bölgenin iklim ve toprak koşullarına bağlı olarak farklılık gösterdiğini ortaya koymuştur (Aziz et al., 2013; Lakusic et al., 2013; Mammadov 2014).

Bu çalışmanın amacı, Eskişehir ekolojik koşullarında üretimi yapılan tıbbi adaçayı (S. officinalis L.) bitkisi için uçucu yağ oranı ve kompozisyonu dikkate alınarak en uygun hasat zamanını belirlemektir.

\section{MATERYAL VE METOT}

Araştırmada bitki materyali olarak Tarla Bitkileri Merkez Araştırma Enstitüsü'nün çeşit bahçesinden temin edilen tıbbi adaçayı (Salvia officinalis L.) tohumlardan üretilen fideler kullanılmışıır.

Çalışmanın yürütüldüğü Eskişehir ilinin uzun yıllar ve 2015 yılına ait, aylar itibariyle yağış miktarı incelenecek olursa, denemenin yürütüldüğü 2015 yılında uzun yılların üzerinde bir yağış alınmış olup, özellikle Haziran ayında uzun yılların bu aya ait yağışına kıyasla çok daha yüksek bir yağış aldığı görülmektedir (Çizelge 1).

Benzer şekilde çalışmanın yürütüldüğü yıldaki ortalama sıcaklıklar uzun yıllar ortalamasının bir miktar üzerinde seyretmesine rağmen genel anlamda uzun yıllar ortalamasına benzer bir seyir izlemiştir (Çizelge 1).

Çalışma yerine ait toprağın özelliklerini belirlemek amacıyla alınan örnekler üzerinde yapılan analiz sonucunda elde edilen veriler dikkate alındığında; toprak $\mathrm{pH}^{\prime}$ I 7.44 olup, hafif alkali bir durum arz etmektedir. Organik madde (\%3.18) bakımından ise toprak orta düzeydedir. Yararlanılabilir potasyum ve fosfor düzeyleri sırasıyla $246 \mathrm{~kg} \mathrm{da}^{-1}$ ve $29.1 \mathrm{~kg} \mathrm{da}^{-1}$ dır. Kireç oranı ise \%5.78 olarak belirlenmiştir. Ayrıca toprak tuzluluğu $0.32 \mathrm{ds} \mathrm{m}^{-1}$ olduğu görülmektedir (Çizelge 2).

Tıbbi adaçayı tohumlarından elde edilen fideler kullanılarak 2014 yılında plantasyon Eskişehir Osmangazi Üniversitesi Ziraat Fakültesi Araştırma tarlasında kurulmuştur. Deneme için ihtiyaç duyulan fideleri yetiştirmek amacıyla 03.03.2014 tarihinde serada hazırlanmış olan ( $1 / 3$ oranında kum $+2 / 3$ oranında torf içeren) yastıklara tohum ekimi yapılmıştır. Yaklaşık 3 hafta süreyle yastıkta gelişen fideler daha sonra viyollere şaşırtılmıştır. Viyollerde 3 hafta süreyle gelişen ve şaşırtılacak olgunluğa ulaşan fideler 25.04 .2014 tarihinde bitki sıklığı $40 \times 20 \mathrm{~cm}$ olacak şekilde dikimleri yapılmıştır (Bayram ve Sönmez 2006). Deneme Tesadüf Blokları Deneme Desenine göre 3 tekerrürlü olarak kurulmuş ve her tekerrürde 4 parsel bulunmaktadır. Her parselde 4 sıra bitki bulunmakta olup, $1.6 \times 3 \mathrm{~m}=4.8 \mathrm{~m}^{2}$ alana sahiptir. Denemenin ilk yılında bitkilerin gelişimi yavaş olmuş ve ancak tek biçim (25/09/2014) yapılabilmiştir. 
Katar ve ark., Tıbbi Adaçayı (Salvia officinalis L.)'nda Uçucu Yağ Oranı ve Kompozisyonu Üzerine Ontogenetik Varyabilitenin Etkisi

Çizelge 1. Deneme alanına ait bazı iklim verileri.

Table 1. Some climate datas for the experiment area.

\begin{tabular}{|c|c|c|c|c|c|}
\hline \multirow{2}{*}{\multicolumn{2}{|c|}{$\begin{array}{c}\text { İklim Faktörleri } \\
\text { Yıllar } \\
\end{array}$}} & \multicolumn{2}{|c|}{ Toplam Yağış (mm) } & \multicolumn{2}{|c|}{ Ortalama Sıcaklık ( ${ }^{\circ} \mathrm{C}$ ) } \\
\hline & & 2015 & Uzun Yillar (1970-2011) & 2015 & Uzun Yıllar (1970-2011) \\
\hline \multirow{12}{*}{ Aylar } & Ocak & 29.90 & 30.60 & -0.80 & -0.20 \\
\hline & Şubat & 44.80 & 26.10 & 2.70 & 0.90 \\
\hline & Mart & 38.90 & 27.60 & 5.60 & 4.90 \\
\hline & Nisan & 26.60 & 43.10 & 7.90 & 9.60 \\
\hline & Mayıs & 47.80 & 40.00 & 15.50 & 14.90 \\
\hline & Haziran & 151.10 & 23.70 & 17.10 & 19.10 \\
\hline & Temmuz & 0.00 & 13.10 & 22.10 & 22.10 \\
\hline & Ağustos & 37.20 & 9.20 & 22.70 & 21.80 \\
\hline & Eylül & 3.10 & 18.10 & 20.90 & 16.70 \\
\hline & Ekim & 34.00 & 32.80 & 13.10 & 11.70 \\
\hline & Kasım & 8.20 & 34.00 & 7.90 & 5.60 \\
\hline & Aralık & 1.10 & 40.50 & -0.70 & 1.70 \\
\hline \multicolumn{2}{|c|}{ Toplam/Ortalama } & 422.70 & 338.80 & 11.17 & 10,73 \\
\hline
\end{tabular}

Meteoroloji 3. Bölge Müdürlüğü-Eskişehir.

Çizelge 2. Deneme tarlası toprağının bazı fiziksel ve kimyasal özellikleri.

Table 2. Some physical and chemical properties of the soil of experiment area.

\begin{tabular}{|c|c|c|c|c|c|c|}
\hline Bünye & Kireç (\%) & $\begin{array}{c}\text { Tuz } \\
\left(\text { ds } \mathbf{~ m}^{-1}\right)\end{array}$ & $\begin{array}{l}\text { Yarayışlı Fosfor } \\
\left(\mathrm{P}_{2} \mathrm{O}_{5}\right)\left(\mathrm{kg} \mathrm{da}^{-1}\right)\end{array}$ & $\begin{array}{l}\text { Yarayışlı Potasyum } \\
\left(\mathrm{K}_{2} \mathrm{O}\right)\left(\mathrm{kg} \mathrm{da}^{-1}\right)\end{array}$ & pH & Organik Madde \\
\hline Killi-tınlı & 5.78 & 0.32 & 29.1 & 246 & 7.44 & 3.18 \\
\hline
\end{tabular}

Geçit Kuşağı Tarımsal Araştırma Enstitüsü Toprak-Bitki-Su analiz ve Fizyoloji laboratuvarlarında yapılmıştır.

Bu çalışmada kullanılan materyaller plantasyonun 2. yılından (2015) elde edilmiş bitki materyalleridir. Bitki plantasyonlarında özellikle ilkbaharda sorun oluşturan yabancı otlar çapayla temizlenmiştir. Plantasyon her iki yıl için intiyaç durumu dikkate alınarak 15-25 gün aralıklarla sulanmıştır. Plantasyona her iki yılda da gübre uygulaması yapılmamışır. Ontogenetik varyabilitenin uçucu yağ oranı ve bileşenleri üzerine olan etkisini belirlemek için dört farklı dönemde (çiçeklenme öncesi, çiçeklenme başlangıcl, tam çiçek ve tohum bağlama dönemi) bitkilerin hasadı yapılmıştır. Farklı dönemlerde biçimi yapılan parsellerden elde edilen taze herbaların yaprakları ayrılarak $35-38{ }^{\circ} \mathrm{C}$ sıcaklıktaki etüvde sabit ağırlığa ulaşıncaya kadar (24-30 saat) kurutulmuştur. Kurutulmuş yapraklardan alınan örneklerin uçucu yağ oranları su distilasyonu yöntemiyle belirlenmiştir. Uçucu yağların distilasyonu için ayıklanmış ve kurutulmuş $100 \mathrm{~g}$ yaprak örnekleri $2000 \mathrm{ml}$ 'lik balonlara yerleştirildikten sonra $1000 \mathrm{ml}$ saf su eklenerek 3 saat boyunca distilasyon işlemi gerçekleştirilmiştir. Distilasyon işlemi tamamlandıktan sonra clevenger aparatının dereceli kısmından yağ miktarı okunarak yüzde (\%) olarak belirlenmiştir. Clevenger cihazından alınan uçucu yağlar bileşenlere bakılacağı zamana kadar $3-4{ }^{\circ} \mathrm{C}$ sıcaklıktaki buzdolabında saklanmıştır.
Uçucu yağların bileşenleri çalışma koşulları aşağıda verilen GC/MS cihazıyla Batı Akdeniz Tarımsal Araştırma Enstitüsü Müdürlüğü/Tıbbi Araştırmalar Merkezi Laboratuvar'ında belirlenmiştir. Örnekler analiz edilmek üzere 1:100 oranında hekzan ile seyreltilmiştir. Örneklerin uçucu yağ bileşen analizi GC/GC-MS (Gaz kromatografisi (Agilent 7890A)-kütle detektör (Agilent 5975C)) cihazı ile kapiler kolon (HP InnowaxCapillary; $60.0 \mathrm{~m} \times 0.25 \mathrm{~mm} \times 0.25 \mu \mathrm{m}$ ) kullanılarak gerçekleştirilmiştir. Analizde taşıyıcı gaz olarak $0.8 \mathrm{ml} / \mathrm{dk}$ akış hızında helyum kullanılmış, örnekler cihaza $1 \mu$ l olarak 40:1 split oranı ile enjekte edilmiştir. Enjektör sıcaklığı $250^{\circ} \mathrm{C}^{\prime}$ de tutulmuş, kolon sıcaklık programı $60{ }^{\circ} \mathrm{C}$ (10 dakika), $60{ }^{\circ} \mathrm{C}$ 'den 250 ${ }^{\circ} \mathrm{C}$ 'ye $20{ }^{\circ} \mathrm{C}$ /dakika ve $250{ }^{\circ} \mathrm{C}$ (10.5 dakika) olacak şekilde ayarlanmıştır. Bu sıcaklık programı doğrultusunda toplam analiz süresi 30 dakika olmuştur. Kütle detektörü için tarama aralığı $(\mathrm{m} / \mathrm{z}) 35$ 450 atomik kütle ünitesi ve elektron bombardımanı iyonizasyonu $70 \mathrm{eV}$ kullanılmıştır. Uçucu yağın bileşenlerinin teşhisinde ise WILEY ve OIL ADAMS kütüphanelerinin verileri esas alınmıştır. Sonuçların bileşen yüzdeleri FID dedektör kullanılarak, bileşenlerin teşhisi ise MS dedektör kullanılarak yapılmıştır.

Uçucu yağ oranlarına ait veriler TARIST paket programı (Açıkgöz ve ark., 1994) kullanılarak, tesadüf blokları deneme desenine göre varyans analizine tabi 
Katar ve ark., Tıbbi Adaçayı (Salvia officinalis L.)'nda Uçucu Yağ Oranı ve Kompozisyonu Üzerine Ontogenetik Varyabilitenin Etkisi

tutularak incelenen özelliklerin önemlilik düzeyleri belirlenmiştir. Önemli çıkan uygulamalar arasındaki farklılıklar hesaplanan LSD değerine göre gruplandırılmıştır (Düzgüneş ve ark., 1987).

\section{BULGULAR VE TARTISMMA}

\section{Uçucu Yağ Oranı}

Dünyada üretimi yapılan önemli tıbbi aromatik bitkilerin büyük bir kısmının etkili maddesi uçucu yağlardır (Mammadov 2014). Bitkiler için önemli bir sekonder metabolit olan uçucu yağların oranı birçok faktöre bağlı olarak değişiklik göstermektedir. Uçucu yağların oranı üzerinde; üretimde kullanılan bitkilerin genotipi, üretimin yapıldığı bölgenin iklim ve toprak özellikleri ve yetiştiricilik teknikleri etkili olmaktadır (Hadiana et al., 2008). Uçucu yağın oranı üzerinde etkili olan en önemli yetiştiricilik tekniklerinden birisi de bitkilerin hasadının yapıldığı zamandır. Aromatik bitkilerin içermiş olduğu uçucu yağın oranının bitkinin gelişim dönemine bağlı olarak değişiklik gösterdiği yapılan araştırmalarla ortaya konmuştur (Toncer et al., 2009; Lakusic et al., 2013; Uyanık ve Gürbüz 2015). Bu durum standart kalitede ürün üretmek isteyen üreticiler için büyük öneme sahiptir. Çünkü üretimle ilgili uygulamaların tümü eksiksiz yerine getirilse bile yanlış zamanda yapılacak olan hasat ürünün uçucu yağ içeriğini büyük oranda olumsuz yönde etkilemektedir. $\mathrm{Bu}$ da ürünün piyasa değerini düşürmektedir. Bu olumsuzluğun ortadan kaldırılması için üretilecek olan aromatik bitkilerin üretim bölgelerine göre en uygun hasat zamanlarının yapılacak olan çalışmalarla belirlenmesine ihtiyaç duyulmaktadır.

Tıbbi adaçayında, Eskişehir koşullarında yürütülen çalışmayla bitkinin farklı gelişim dönemlerinde yapılan hasadın uçucu yağ oranı üzerinde önemli düzeyde (\%1) etkili olduğu görülmüştür. Değişen hasat zamanına bağlı olarak drog yapraklardaki uçucu yağ oranı \% 1-2 arasında değişiklik göstermiştir (Çizelge 3). En yüksek uçucu yağ oranı (\% 2) çiçeklenme öncesinde yapılan hasattan alınırken, en düşük oran ise (\% 1) tam çiçeklenme ve tohum bağlama döneminde yapılan hasattan alınmıştır. $\mathrm{Bu}$ da bölgemiz için tıbbi adaçayında değişen hasat zamanlarının uçucu yağ oranı üzerinde \%100'e varan düzeyde değişikliğe neden olduğunu ortaya koymaktadır. Bu durum da bölgede yapılacak olan tıbbi adaçayı üretiminden standart ve kaliteli ürün elde etmek için yapılacak olan hasadın zamanının bilinmesinin büyük öneme sahip olduğunu göstermektedir. Yapılan çalışma uçucu yağ oranının çiçeklenme öncesinden tam çiçeklenmeye kadar geçen zaman içerisinde azaldığını göstermiştir. Fakat bu değişimin tam çiçeklenmeden sonra tohum bağlamaya kadar geçen sürede devam etmediği tespit edilmemiştir (Çizelge 3).

Bu durum genç bitkilerde uçucu yağ oranının yaşlı bitkilere kıyasla daha yüksek olması ve aromatik bitkilerde uçucu yağların en fazla biriktiği dönemin çiçek tomurcuklarının ve çiçeklerin oluştuğu dönem olmasıyla açıklanabilir (Mammadov 2014). Ayrıca bitkinin hasadının yapıldığı farklı gelişim dönemlerine bağlı olarak değişen iklim koşulları (sıcaklık, ışık yoğunluğu, nem vb.) da sekonder metabolitlerin üretimi (oranı) üzerinde etkili olmaktadır. Bu da uçucu yağ oranının hasat zamanlarına bağlı olarak değişimini açıklamaktadır (Ramakrishna and Ravishankar 2011).

\section{Uçucu Yağ Bileşenleri}

Çalışmada yapılan analizlerin sonucunda elde edilen uçucu yağ bileşenlerine ait veriler, her ne kadar farklı hasat zamanlarına bağlı olarak bir miktar değişiklik gösterse de uçucu yağın \%98-99'luk kısmını 18 farklı bileşenin oluşturduğunu ortaya ortaya koymuştur (Çizelge 3). Bu bileşenlerin içerisinde alfathujon ve kafur ana bileşenler olarak öne çıkmaktadır. Alfa-thujon gelişim dönemlerine bağlı olarak \%23.0947.24 arasında değişim göstermiştir. En yüksek alfathujon oranına tam çiçeklenme döneminde ulaşırken, en düşük orana ise çiçeklenme başlangıcında ulaşılmıştır. Kafur oranı ise yine bitkinin gelişim dönemine bağlı olarak \%12.41-20.63 arasında değişiklik göstermiştir. En düşük kafur oranı tam çiçekte yapılan hasattan alınırken, en yüksek kafur oranı ise çiçeklenme öncesi yapılan hasattan alınmıştır. Tıbbi adaçayı uçucu yağının diğer önemli bir bileşen olan 1.8-sineol ise \%4.10-6.30 arasında değişiklik göstermiştir. En yüksek 1.8-sineol oranı tohum bağlama döneminde yapılan hasattan elde edilirken, en düşük oran ise çiçeklenme başlangıcında yapılan hasattan elde edilmiştir. Bitkinin çiçeklenme başlangıcında yapılan hasattan düşük oranda alfathujon ve kafur elde edilirken, bu dönemde bornil asetat (\% 10.49) ve germakren (\%9.36) oranı yüksek bulunmuştur. Farklı hasat zamanları bornil asetat oranı üzerinde de büyük oranda değişikliğe neden olmuştur. Yapılan çalışmada elde edilen uçucu yağlarda bu bileşenin \%0.64-10.49 arasında değiştiği tespit edilmiştir. Aynı durum germakren içinde geçerli olup, bu bileşen de ise farklı hasat zamanlarına bağlı olarak \%1.20-9.39 arasında değişim belirlenmiştir (Çizelge 3).

Farklı hasat zamanlarının uçucu yağ bileşenleri üzerindeki etkisi genel olarak değerlendirildiğinde çiçeklenme öncesi ve çiçeklenme başlangıcında bileşenlerin oranları birbirine yakın iken, tam çiçeklenme ve tohum bağlama dönemine ait değerler de birbirine yakın olduğu tespit edilmiştir. Bu durum 
Katar ve ark., Tıbbi Adaçayı (Salvia officinalis L.)'nda Uçucu Yağ Oranı ve Kompozisyonu Üzerine Ontogenetik Varyabilitenin Etkisi

Çizelge 3. Salvia officinalis'de gelişim dönemlerine bağlı olarak uçucu yağ oran ve bileşenlerinin değişimi (\%). Table 3. Change of essential oil content and components depending on developmental stages in Salvia officinalis (\%).

\begin{tabular}{|c|c|c|c|c|}
\hline \multirow[b]{2}{*}{ Uçucu Yağ Bileşenleri } & \multicolumn{4}{|c|}{ Gelişme Dönemleri } \\
\hline & Çiçeklenme Öncesi & Çiçeklenme Başlangıcı & $\begin{array}{c}\text { Tam Çiçeklenme } \\
\text { Dönemi }\end{array}$ & $\begin{array}{c}\text { Tohum Bağlama } \\
\text { Dönemi }\end{array}$ \\
\hline$\alpha$-pinene & 1.45 & 2.63 & 4.72 & 4.91 \\
\hline camphene & 4.13 & 6.11 & 3.04 & 3.14 \\
\hline$\beta$-pinene & 2.16 & 3.89 & 2.49 & 2.49 \\
\hline$\beta$-myrcene & 1.13 & 0.91 & 1.15 & 1.17 \\
\hline limonene & 1.66 & 1.87 & 1.33 & 1.37 \\
\hline 1,8-cineole & 4.28 & 4.10 & 6.17 & 6.30 \\
\hline gamma-terpinene & 0.75 & 0.69 & 0.54 & 0.55 \\
\hline$\alpha$-thujone & 35.70 & 23.09 & 47.24 & 46.73 \\
\hline trans-sabinenehydrate & 4.44 & 2.21 & 6.62 & 6.60 \\
\hline linalool & 0.44 & 0.83 & 0.28 & 0.28 \\
\hline camphor & 20.63 & 19.73 & 12.41 & 12.81 \\
\hline bornyl acetate & 4.67 & 10.49 & 0.67 & 0.64 \\
\hline$\beta$-caryophyllene & 1.58 & 1.66 & 2.42 & 2.53 \\
\hline isothujol & 0.96 & 0.79 & 0.47 & 0.49 \\
\hline$\alpha$-humulene & 3.20 & 3.78 & 3.11 & 3.19 \\
\hline germacrene & 5.53 & 9.39 & 1.20 & 1.21 \\
\hline humulene epoxide & 0.48 & 0.47 & 0.71 & 0.71 \\
\hline viridiflorol & 5.32 & 5.70 & 3.27 & 3.19 \\
\hline tanımlanamayanlar & 0.70 & 1.01 & 1.10 & 0.51 \\
\hline Toplam & 99.21 & 99.35 & 98.94 & 98.82 \\
\hline Yağ Oranları (\%) & $2.00^{A}$ & $1.80^{B}$ & $1.00^{c}$ & $1.00^{c}$ \\
\hline
\end{tabular}

**: Significant at 1\%; C.V.: Coefficient of Variance; LSD.: Least Significant Difference.

bize uçucu yağ bileşenleri arasındaki büyük farklılığın çiçeklenme başlangıcı ile tam çiçeklenme arasında olduğunu göstermektedir.

Aromatik bitkilerin uçucu yağlarının kimyasal kompozisyonları üretimde kullanılan bitkilerin genotipleri, üretimin yapıldığı bölgenin ekolojik koşulları ve yetiştiricilik uygulamalrının etkisi altında farklılık göstermektedir. Uçucu yağ kompozisyonunun değişimi üzerinde etkili olan faktörlerden biri de hasadın yapıldığı bitki gelişim dönemidir. Bitkilerde uçucu yağın bileşenlerinin oranı hasadın yapıldığı gelişim dönemine bağlı olarak büyük oranda değişim göstermektedir. Bu değişim daha çok uçucu yağı oluşturan ana bileşenlerde dikkat çekmektedir. Bu çalışmada tıbbi adaçayının uçucu yağının ana bileşenleri olan alfa-thujon, kafur, bornil asetat, germakren ve 1.8-sineol hasadın yapıldığı farklı gelişim dönemlerine bağlı olarak değişiklik göstermiştir. Bu durum bitkinin gelişim dönemlerine bağlı olarak değişen çevre koşullarının bitkinin fizyolojik durumu (biyosentez yolu) üzerine olan etkisi ve vejetasyon süresinin ilerlemesi ile bitki organlarında meydana gelen yaşlanmayla açıklanabilir (Lakusic et al., 2013; Mammadov 2014).

\section{SONUÇ}

Tıbbi adaçayı yaprak droglarından baharat ve herbal çay olarak faydalanılırken toksik etkileri belirlenmiş olan alfa-thujon ve kafur oranlarının mümkün olduğunca düşük olması istenmektedir. Ayrıca uçucu yağ oranının \%1.5'un üzerinde olması da ürünün kalitesi açısından büyük bir öneme sahiptir (Ekren ve ark., 2007; Shahabi et al., 2012). Yapılan çalışmadan elde edilen veriler birlikte değerlendirildiğinde Eskişehir koşullarında yapılacak olan tıbbi adaçayı üretiminde en yüksek uçucu yağ oranı, en düşük alfa-thujon ve kafur içeriğine sahip drog elde etmek için hasadın çiçeklenme başlangıcında yapılmasının uygun olduğu anlaşılmaktadır. 


\section{KAYNAKLAR}

Açıkgöz N., Akbaş ME., Moghaddam A ve Özcan K., 1994. PC'ler İçin veritabanı Esaslı Türkçe İstatistik Paketi: TARIST, 1. Tarla Bitkileri Kongresi Bildiri Kitabı, 24-28 Nisan, İzmir.

Aziz EE., Sabry RM and Ahmed SS., 2013. Plant growth and essential oil production of sage (Salvia officinalis L.) and curly-leafed parsley (Petroselinum crispum ssp. crispum L.) Cultivated under salt stress conditions. World Applied Sciences Journal, 28(6): 785-796.

Başa AG., Roman GV., Ion V., Toader M and Epure LI., 2012. Research on productivity and yield quality of Salvia officinalis L. species grown in organic agriculture conditions. Scientific Papers Series A Agronomy, LV: 271 278.

Bayram E., Kırıcı S., Tansı S., Yılmaz G., Arabacı O., Kızıl S ve Telci I., 2010. Tıbbi ve Aromatik Bitkiler Üretiminin Arttırılması Olanakları. Ziraat Mühendisligi VII. Teknik Kongresi Bildiri Kitabı I, 11-15 Ocak, Ankara.

Düzgüneş O., Kesici T., Kavuncu O ve Gürbüz F., 1987. Araştırma ve Deneme Metotları. Ankara Üniversitesi, Ziraat Fakültesi Yayınları, Ankara.

Ekren S., Sözmez Ç., Sancaktaroğlu S ve Bayram E., 2007. Farklı biçim yüksekliklerinin adaçayı (Salvia officinalis L.) genotiplerinde agronomik ve teknolojik özelliklere etkisinin belirlenmesi. Ege Üniversitesi Ziraat Fakültesi Dergisi, 44(1): 55-70.

Hadiana J., Tabatabaeia SMF., Naghavib MR., Jamzadc Z and Ramak-Masoumia T., 2008. Genetic diversity of Iranian accessions of Satureja hortensis L. based on horticultural traits and RAPD markers. Scientia Horticulturae, 115(2): 196-202.

Kilic Ö., 2016. Chemical composition of four Salvia L. species from Turkey: a chemotaxonomic approach. Journal of Essential Oil Bearing Plants, 19(1): 229-235.

Lakusic BS., Ristic MS., Slavkovska VN., Stojanovic DL and Lakusic DV., 2013. Variations in essential oil yields and compositions of Salvia officinalis (Lamiaceae) at different developmental stages. Botanica Serbica, 37(2): 127-139.

Mammadov R., 2014. Tohumlu Bitkilerde Sekonder Metabolitler. Nobel Akademik Yayıncılık, Ankara.

Özcan ii., Arabacı O ve Öğretmen NG., 2014. Bazı adaçayı türlerinde farklı tohum çimlendirme uygulamalarının belirlenmesi. Türk Tarım-Gıda Bilim ve Teknoloji Dergisi, 2(5): 203-207.

Ramakrishna A and Ravishankar GA., 2011. Influence of abiotic stress signals on secondary metabolites in plants. Plant Signaling \& Behavior, 6(11): 1720-1731.

Shahabi S., Jorsaraei SGA., Moghadamnia AA., Zabihi E., Aghajanpour SM., Kani SNM., Pourbagher R., Hosseini SA., Esmaili M., Yoonesi AA., Zarghami $A$ and Alinezhad F., 2012. Central effects of camphor on gnrh and sexual hormones in male rat. International Journal of Molecular and Cellular Medicine, 1(4): 191-196.

Şenkal BC., İpek A., Gürbüz B., Türker A ve Bingöl MÜ., 2012. Bolu ekolojik koşullarında yetiştirilen Salvia officinalis $L$. ve Salvia tomentosa $\mathrm{L}$. türlerinin bazı önemli tarımsal özelliklerinin belirlenmesi. Tarım Bilimleri Araştırma Dergisi, 5(2): 38-42.

Toncer O., Karaman S., Kızıl S ve Dıraz E., 2009. Changes in essential oil composition of oregano (Origanum onites L.) due to diurnal variations at different development stages. Notulae Botanicae Horti Agrobotanici ClujNapoca, 37(2): 177-181.

Uyanık M ve Gurbuz B., 2015. Effect of ontogenetic variability on essential oil content and its composition in lemon balm (Melissa officinalis L.). Tekirdağ Ziraat Fakültesi Dergisi, 12(1): 91-96.

Yılmaz D ve Gokduman ME., 2015. Adaçayı (Salvia officinalis L.) Bitkisinin farklı nem düzeylerinde fiziko-mekanik özelliklerinin belirlenmesi. Süleyman Demirel Üniversitesi Ziraat Fakültesi Dergisi, 10(1): 73-82. 